Article

\title{
Examining Farmers' Adoption Decisions towards Precision-Agricultural Practices in Greek Dairy Cattle Farms
}

\author{
Georgios Kleftodimos ${ }^{1,2, *(\mathbb{C}}$, Leonidas Sotirios Kyrgiakos ${ }^{3}\left(\mathbb{C}\right.$, Christina Kleisiari $^{3}\left(\mathbb{D}\right.$, Aristotelis C. Tagarakis ${ }^{1}(\mathbb{D}$ \\ and Dionysis Bochtis ${ }^{1}$ (i)
}

check for

updates

Citation: Kleftodimos, G.; Kyrgiakos, L.S.; Kleisiari, C.; Tagarakis, A.C.; Bochtis, D. Examining Farmers' Adoption Decisions towards Precision-Agricultural Practices in Greek Dairy Cattle Farms. Sustainability 2022, 14, 411. https:/ / doi.org/10.3390/su14010411

Academic Editors: Konstadinos Mattas, George Baourakis and Stefanos A. Nastis

Received: 29 November 2021 Accepted: 29 December 2021 Published: 31 December 2021 Publisher's Note: MDPI stays neutral with regard to jurisdictional claims in published maps and institutional affiliations.

Copyright: (c) 2021 by the authors. Licensee MDPI, Basel, Switzerland. This article is an open access article distributed under the terms and conditions of the Creative Commons Attribution (CC BY) license (https:// creativecommons.org/licenses/by/ $4.0 /)$.
1 Centre of Research and Technology-Hellas (CERTH), Institute for Bio-Economy and Agri-Technology (IBO), 6th km Charilaou-Thermi Rd., 57001 Thessaloniki, Greece; a.tagarakis@certh.gr (A.C.T.); d.bochtis@certh.gr (D.B.)

2 Mediterranean Agronomic Institute of Montpellier (CIHEAM-IAMM), University of Montpellier, 34093 Montpellier, France

3 Department of Agriculture Crop Production and Rural Environment, University of Thessaly, Fytoko, 38446 Volos, Greece; lkyrgiakos@uth.gr (L.S.K.); chkleisiari@uth.gr (C.K.)

* Correspondence: kleftodimos@iamm.fr or g.kleftodimos@certh.gr

\begin{abstract}
Nowadays, the sustainability of Greek dairy cattle farms is questionable due to low competitiveness and high GHG emissions. In this context, the BIOCIRCULAR project, funded by the EYDE ETAK, developed a series of alternative practices focusing on precision agriculture principles. However, the adoption of any practice from farmers is not a given, and depends on several determinants. Hence, the objective of this study is to examine farmers' adoption decisions regarding precision-agricultural practices in Greek dairy production systems, as well as the economic and environmental impacts of this adoption. In order to achieve this, a bio-economic model was developed based on mathematical programming methods. The proposed model simulates a large number of dairy cattle farms with or without crop production, including different management strategies and their relevant costs, and provides an environmental assessment of the adopted practices based on GHG emissions. Moreover, in order to analyze farmers' adoption decisions, different policy measures, linked to various environmental outcomes, were examined. The results highlighted that the adoption of precision-agricultural practices led to significantly better economic and environmental outcomes. Furthermore, it was found that different levels of incentives can be efficiently targeted to encourage the adoption of new feeds and, more broadly, to secure the sustainability of the sector.
\end{abstract}

Keywords: farmers' adoption decisions; policy scenarios; bio-economic model; dairy cattle farms

\section{Introduction}

The dairy sector is of paramount importance for the Greek economy, as it is responsible for more than the $19 \%$ of the total economic welfare of the national agricultural sector [1]. The main areas of dairy production are located in Central and Northern Greece. Indeed, more than the $80 \%$ of cow production systems are located in the regions of Macedonia, Thrace, and Thessaly. Nowadays, the total number of dairy cows is estimated to be around 106,000 , while the annual milk production is around 600,000 tons [2]. In addition, in recent years, a significant amount of investment in dairy production systems has taken place in Greece in order to strengthen the sector and benefit the impacted stakeholders [3]. However, despite these investments, there is a structural imbalance between the supply and the demand of cow milk, as the national supply can cover only $40 \%$ of the demand [4]. Hence, the Greek dairy production systems suffer from low competitiveness due to inefficient management $[3,4]$.

Moreover, livestock production systems in general have been characterized as one of the main sources of greenhouse gas (GHG) emissions [5]. In fact, livestock produces significant amounts of methane $\left(\mathrm{CH}_{4}\right)$ as an output of enteric fermentation. This ecosystem 
disservice, in combination with the high need for pesticides for the cultivation of the necessary feeds for cows, means that the value chain of dairy cow production constitutes an important polluter [6]. Indeed, the produced methane from the enteric fermentation of the livestock accounts for $32 \%$ of the total EU emissions produced by agricultural activity, while the manure management of the livestock contributes another $16 \%$ of supplementary emissions [7].

Therefore, the EU, through the Common Agricultural Policy, mobilized a series of measures in order to reduce these emissions through innovations and alternative management strategies [7]. In this context, the Bioproduction System for Circular Precision Farming (BioCircular) project, co-financed by the Greek General Secretariat of Research and Technology, aims to promote an alternative management strategy, based on the principles of Circular Economy, while utilizing precision farming concepts and technologies in selected dairy cow vertical production systems [8]. This alternative management strategy is twofold: firstly, it focuses on the local cultivation of crops, aimed at the feeding of cows, using precision agriculture, in order to optimize water and fertilizer use based on the spatial requirements of each field [9]. Secondly, it aims to promote the management of animal precision feeding and welfare, in terms of air ventilation and cleaning management, in order to reduce the production of greenhouse emissions [10].

The adoption of the above practices may significantly reduce the environmental footprint of Greek dairy production systems as well as reducing their production costs and, consequently, increasing their sustainability. However, the adoption of novel practices by the farmers is not a given, as several determinants exist [11]. In fact, the adoption of innovative or novel management strategies by farmers demands the evaluation of the potential gains or losses that may emerge during the process; hence, the cost-effectiveness of the proposed practices or innovation strategies is considered to be an important determinant [12]. Moreover, another important determinant of farmers' adoption processes is labor reallocation. Indeed, if novel practices require significant labor reallocations or are labor intensive, they are perceived as riskier by farmers $[13,14]$. Thus, in general, the adoption of innovative or novel management strategies by farmers is perceived as a source of increased risk [11].

The adoption of the above practices may significantly reduce the environmental footprint of Greek dairy production systems as well as reducing their production costs and, consequently, increasing their sustainability. Therefore, the objective of this study is to examine farmers' adoption decisions towards these new management strategies, as well as the economic and environmental impact of this adoption. In order to achieve this, a bio-economic model was developed based on mathematical programming methods [14,15]. The proposed model: (i) simulates a large number of dairy cattle farms with or without crop production; (ii) includes a gradient of production intensification or input reduction based on the agro-ecological principles of dairy and crop production; (iii) incorporates all relevant costs (e.g., labor, machinery, land, etc.); (iv) integrates the current public policy framework; and (v) provides an environmental assessment of the selected feeds based on GHG emissions and soil carbon sequestration. Moreover, in order to analyze farmers adoption decisions regarding these new strategies, different levels of policy incentives, linked to various environmental outcomes, were examined.

The Section 2 presents a step-by-step analysis of the elaborated methodology, while Section 3 highlights the main findings. After discussing the main findings in the Section 4, the final section draws some conclusions and presents the limitations of our modeling attempt.

\section{Materials and Methods}

This section presents the bio-economic model and its constraints, the selection of the examined farms, and the proposed policy measures. 


\subsection{The Structure of the Bio-Economic Model}

The bio-economic model maximizes farmer's gross-margins over one period under constraints for two selected farms in the region of Thessaly, in Greece. We assumed that farmers are risk-averse towards the proposed management strategies [16]. The proposed model is a linear one constructed by the use of mathematical programming methods in GAMS software (General Algebraic Modeling System).

The objective function has the following form:

$$
U=\Sigma g m_{c, n}-\Sigma(\varphi * s t d)
$$

where $g m$ is the gross-margin, $\varphi$ is the risk aversion coefficient, st $d$ the standard deviation of the average income, and the index $c$ stands for the conventional practices, while the index $n$ stands for the adoption of alternative management strategies. The standard deviation of average income is calculated as follows.

$$
s t d=\sqrt{\Sigma\left(R A L r d t-g m_{c, n}\right)^{2}}
$$

where RALrdt is the random income according to each state of nature.

For the estimation of the value of the risk aversion coefficient, we tested several different values that were within the interval of $\{0.5,1.5\}$ [17]. Hence, during the calibration of the model, we tested the above values by using the Percentage of Absolute Deviation (PAD) as an indicator to validate the accuracy of the model. Following this methodology, we retained a value of the risk aversion coefficient equal to 1 , which corresponds to a moderate risk aversion according to the literature [18]

\subsection{The Bio-Economic Model Constraints}

In this sub-section, we present the main constraints of the bio-economic model. These constraints relate to a variety of economic, agronomic, environmental, and public policy issues.

i. Land constraint

The sum of the cultivated surfaces should be less than or equal to the total area of the farmland.

$$
\sum_{c r o p, p c, s} x(\text { crop }, p c, s) \leq \text { farmland }
$$

where $x$ is the surface of each crop, associated with the previous crop ( $p r)$, for each type of soil (s).

\section{ii. Water constraint}

The water resources in each farm are limited; hence, the total use of water should be less than or equal to the total water availability. Thus,

$$
\sum_{c, m, p c, s, i, q s}(\operatorname{cai}(\operatorname{crop}, m) \times x(\operatorname{crop}, p c, s)+c a(\text { animal }, m) \times \operatorname{cow}) \leq \text { WATER }
$$

where cai(crop, $m)$ is the water use calendrer per month per crop $\left(\mathrm{m}^{3} / \mathrm{ha}\right)$, ca(animal,m) is the water use calendar per month per animal $\left(\mathrm{m}^{3} / \mathrm{ha}\right)$, and WATER is the total water availability per farm.

iii. Labor constraint

The labor availability of each farm is composed of family labor and occasional seasonal workers. Hence,

$$
\sum_{\text {crop, cow }, h} \text { Labor }_{\text {crop }, h}+\text { Labor }_{\text {cow }, h} \leq \text { workfam }_{h}+\text { workers }_{h}
$$


where Labor crop, $h_{\text {is }}$ is the total hours devoted to crop production, Labor cow,$h_{\text {is }}$ the hours devoted to dairy production, work $\mathrm{fam}_{h}$ is the total family labor availability, and workers $s_{h}$ is the hired labor.

\section{iv. Crop rotation}

Here, we propose a crop rotation constraint that restricts the selection of crops by the farmer. According to this constraint, the cultivation surface of a crop is limited by its allowed precedents. In order to produce a matrix of crop precedents, we used data obtained by personal interviews. Consequently, the constraint has the following form:

$$
\sum_{\text {crop }, s} x(c r o p, s) \leq \sum_{p c, s} x(p c, s)
$$

where $\sum_{p c, s} x(p c, s)$ is the surface of the precedent crop in each soil type.

v. Public policy constraints:

The model includes all the necessary constraints of the Common Agricultural Policy that are required receive the Basic and Greening payments [19]. For animal production, due to a lack of data, we assumed that the farmer respects all of the regulations regarding feeding and animal welfare. Concerning crop production, the farmer has to follow constraints relating to the following three areas: permanent grasslands, crop diversity, and Ecological Focus Areas (EFA) [19]. However, as the examined production systems use less than 15 ha, they were excluded from the requirement of maintaining EFAs. Hence, the constraints have the following form:

\section{a. Permanent grasslands}

Permanent grassland must always be maintained in the agricultural systems and should be no less than the $5 \%$ of the total surface of the farm. Hence,

$$
\sum_{\text {crop }} x^{\prime \prime} g l^{\prime \prime} \geq 0.95 \times \sum_{\text {crop }} x^{\prime \prime} g^{0^{\prime \prime}}
$$

where $\sum_{\text {crop }} x^{\prime \prime} g^{\prime \prime}$ is the permanent grasslands, while $\sum_{\text {crop }} x^{\prime \prime}{ }_{g l^{\prime \prime}}$ is the permanent grassland observed in the baseline year.

\section{b. Crop diversity}

According to this constraint, every farm that exceeds the 10 ha must cultivate at least two different crop species every season. Following the article of Kleftodimos et al. [4], we adopted the following constraint:

$$
\sum_{\text {crop }} x^{\prime \prime} m^{\prime \prime} \leq 0.75 \times \text { farmland }
$$

where $\sum_{\text {crop }} x^{\prime \prime} m^{\prime \prime}$ is the cultivated surface of the main crop, and farmland is the total cultivated land of the farm.

\subsection{Farm Selection}

For the simulations of our model, we selected two characteristic farms in the region of Thessaly. With the help of experts from the local extension services and the University of Thessaly, we observed and selected two actual real farms that are characteristic of the existing agricultural systems in the grater area of Thessaly (Table 1). These include farm 1 , which is an intensive cow dairy farming system with 40 milking cows and no available arable land, and farm 2, with 48 milking cows and 12 ha of arable crop land, which is mostly used to cultivate crops for animal feeding. Moreover, farm 1 is characterized by low family labor availability and high dependency on seasonal workers, while farm 2 has 
significantly higher labor availability and it experiences lower production costs, mostly due to the fact that the production of crops constitutes an input in milk production

Table 1. Farms' characteristics ( $n$ represents the number of farms per farm).

\begin{tabular}{ccc}
\hline Variables & Farm 1 & Farm 2 \\
\hline Cropped area (ha) & - & 12 \\
\hline Gross-margin $(€ /$ cow) & 1389.13 & 1523.09 \\
\hline Total cows (number) & 40 & 48 \\
\hline Family labor (h/year) & 1424.2 & 2117.3 \\
\hline Milk production costs $(€ /$ cow) & 3800.13 & 3300.65 \\
\hline Water use $\left(\mathrm{m}^{3}\right)$ & 4460 & 16,253 \\
\hline Building facilities (ha) & 2.71 & 5.15 \\
\hline & Crop pattern & 4 \\
\hline Soya & - & 5 \\
\hline Corn & - & 2.3 \\
\hline Pulses & - & 0.7 \\
\hline Permanent grassland & - &
\end{tabular}

\subsection{Proposed Management Strategies and Public Policy Incentives}

As mentioned above, the alternative management strategies are focused on precision agriculture and circular economy principles. Hence, the BioCircular project mobilizes a series of alternative management strategies that are supervised through a digital platform. This platform has three different sub-systems running the whole value chain [8]. These sub-systems include: (i) crop production for animal feeding, (ii) animal production for milking cows, and (iii) milk processing and transportation, which does not fall within the interests of this study.

Regarding crop production, the proposed strategies aim at the extensive monitoring of weather and soil moisture through the adoption of Internet of Things (IoT) sensing systems. These systems monitor the above indicators through remote and proximal sensing (satellites, drones, etc.) in order to provide important information to the farmers regarding crop irrigation needs and fertilizer use. Hence, this information is of paramount importance as it may contribute towards the decreasing of the above inputs in the system and, consequently, towards decreasing the environmental footprint of the agricultural activity [8].

Concerning animal production, the same IoT sensing system will provide information to the farmers regarding precision animal feeding, animal housing environmental conditions, and animal waste systems. In fact, the precision feeding of the animals is an important factor that may significantly reduce methane emissions [9]. Moreover, the maintenance of suitable temperatures within the animal building as well as the sufficient cleaning of the manure from the floor (every 1-2 h) may contribute significantly towards further decreases in methane and nitrous oxide [10]. Finally, an effective animal waste treatment, involving the reuse of manure as a fertilizer for the crop production, has multiple advantages, such as less water use and decreases in the emissions of nitrous oxide and carbon dioxide [10]. However, the adoption of the above practices comes with an important increase in labor demand for the farming systems [13]. Therefore, we considered that the proposed practices are perceived as riskier by the farmers and that they imply a threefold increase in the labor demands of animal production and a twofold increase in the labor demands of crop production.

More specifically, following the BioCircular project, the IoT sensing system will not require the allocation of funding by the farmers, and the local extension services will be responsible for the training sessions. In any case, our modeling attempt did not consider the 
above potential costs, and focused only on the farmers' adoption processes of the proposed management strategies. In fact, the IoT system comes with all the above alternative management strategies, which require significant labor reallocation from the farmer. In the following table (Table 2), we present the proposed management strategies per operation as well as their impact on farm management and on risk.

Table 2. Proposed management strategies.

\begin{tabular}{|c|c|c|}
\hline Management Practices & Impact on Farm Management & Impact on Risk \\
\hline \multicolumn{3}{|c|}{ Crop Production } \\
\hline $\begin{array}{c}\text { Extensive monitoring of } \\
\text { fertilizer needs }\end{array}$ & \multirow{2}{*}{$\begin{array}{l}\text { Twofold increase in labor required for } \\
\text { these operations, and thus, in the } \\
\text { associated costs }\end{array}$} & \multirow{2}{*}{ Risk aversion } \\
\hline $\begin{array}{l}\text { Extensive monitoring of } \\
\text { water needs }\end{array}$ & & \\
\hline \multicolumn{3}{|c|}{ Animal Production } \\
\hline Precision feeding & $\begin{array}{l}\text { Threefold increase in labor required for } \\
\text { this operation, and thus, in the } \\
\text { associated costs }\end{array}$ & \multirow{3}{*}{ Risk aversion } \\
\hline Cleaning of the manure & $\begin{array}{l}\text { Fivefold increase in labor required for } \\
\text { this operation, and thus, in the } \\
\text { associated costs }\end{array}$ & \\
\hline Manure treatment & $\begin{array}{l}\text { Threefold increase in labor required for } \\
\text { this operation, and thus, in the } \\
\text { associated costs }\end{array}$ & \\
\hline
\end{tabular}

In order to examine farmers' adoption decisions regarding the above management strategies, two different scenarios were created. Scenario 1 imposes a penalty on the level of produced GHG emissions per $\mathrm{kg}$ of milk produced. This scenario was inspired by the study of Mosnier et al. [20], which examined the effects of GHG mitigation measures in the French dairy sector. On the contrary, Scenario 2 proposes the adoption of the above practices through an incentive. This incentive may have the form of a traditional AES or be based on the new eco-schemes that are expected in the new CAP. Consequently, the farmers who adopt the proposed practices will receive a premium per milking cow.

Here, it must be noted that the levels of the proposed penalties and premiums should be enough to encourage the farmers to fully adopt the proposed practices. Both penalties and subsidies were added to the model as parameters. Consequently, we ran several simulations that investigated different values of subsidies from $€ 0$ per $\mathrm{kg}$ of milk up to $€ 2$ per $\mathrm{kg}$ of milk, and different values of penalties from $€ 0$ per cow up to $€ 100$ per cow.

\subsection{Greenhouse Gas Emissions (GHG) Indicators}

Finally, in this part, we present the selected indicators in order to evaluate the environmental performance of the proposed practices. In order to achieve this, the Life Cycle Assessment approach is used [20]. Here, two gases are considered, both of which are studied in the examined cow dairy farming systems: (i) methane $\left(\mathrm{CH}_{4}\right)$, and (ii) nitrous oxide $\left(\mathrm{N}_{2} \mathrm{O}\right)$.

As mentioned above, methane is produced via the enteric fermentation of animals and, in this study, is expressed in grams of methane per $\mathrm{kg}$ of Digestible Organic Matter (DOM) [20]. Nitrous oxide emissions are produced daily by animals and also as a result of manure management. Hence, we estimated these emissions for every cow in the farming systems separately, as well as from the manure management [5].

\section{Results}

The obtained results for the two farms were compared with the baseline scenario. Consequently, in this section, we present our findings with regard to the farms' gross-margins 
(Table 3), the total costs of the proposed subsidies or the penalties and environmental outcomes regarding GHG emissions.

In general, according to our simulated scenarios, both farms seem to adopt the alternative management practices and, as a result, they experience higher gross margins and lower production costs. More specifically, in scenario 1, farm 1 adopts the novel practices for a penalty of $€ 0.12$ per $\mathrm{kg}$ of milk produced. For lower penalties, the farmer is not motivated to adopt the alternative practices as the labor reallocations are an important barrier. Hence, for lower prices, the farmer prefers to pay the penalty than to confront the issue by other means. Moreover, by adopting these practices, the farmer is profiting from reducing costs, in terms of feeding as well as for the increasing gains for the sale of manure as a fertilizer. However, the farmer experiences a significant increase in labor costs. Similarly, farm 2 seems to adopt the alternative practices more easily. A penalty of $€ 0.04$ per $\mathrm{kg}$ seems sufficient in order to mobilize the farmer. This is happening because farm 2 has a significantly higher labor force than farm 1. In addition, as farm 2 adopts the principle of circular economy, it experiences very low production costs for both crop and animal production.

In scenario 2, the simulation results are significantly different. In fact, farm 1 adopts the alternative practices for a premium of $€ 42$ per cow. This value is needed in order to convince the farmer to overcome the barrier of low labor force and adopt the proposed practices. Moreover, this premium, in combination with the sales of manure, allows the farmer to significantly increase his gross-margin. The same findings are more or less highlighted for farm 2. Indeed, the presence of the premium allows farm 2 to significantly increase its gross-margin and reduce its production costs. However, as this farm has a significantly higher labor force, the requested premium for the adoption is lower than in farm 1 (€29/cow).

Table 3. Economic outcomes (GM was calculated with the presence of a penalty or a subsidy).

\begin{tabular}{ccccccc}
\hline & \multicolumn{3}{c}{ Farm 1 } & & Farm 2 \\
\hline REF & $\begin{array}{c}\text { Gross-Margin } \\
(\mathbf{€} / \text { Cow) }\end{array}$ & $\begin{array}{c}\text { GM } \\
\text { Variation (\%) }\end{array}$ & Cost/Cow & $\begin{array}{c}\text { Gross-Margin } \\
(\mathbf{\ell} / \text { Cow) }\end{array}$ & $\begin{array}{c}\text { GM } \\
\text { Variation (\%) }\end{array}$ & Cost/Cow \\
\hline Baseline & 1389.13 & - & 3800.13 & 1523.09 & - & 3300.65 \\
Scenario 1 & 1401.08 & 1.5 & 3678.23 & 1603.2 & 1.3 & 3261.7 \\
Scenario 2 & 1583.48 & 8.3 & 3020.86 & 2013.35 & 10.17 & 2809.17 \\
\hline
\end{tabular}

Regarding GHG emissions, the examined indicators highlighted important findings. First of all, the alternative practices are the same; both scenarios were found to have the same impact on the indicators for both farms (Table 4). Furthermore, the significant methane reduction that was detected for both farms resulted from the precision feeding of the animals and the good environmental and temperature conditions within the buildings. In addition, nitrous oxide was also found to be reduced significantly in both farms. However, this decrease was observed to be higher in farm 2 for two reasons. Firstly, farm 2 comprises an important agricultural area. As a result, the use of manure as a fertilizer decreases the environmental input in the crop production system. Secondly, farm 2 treats a higher number of animals. Hence, the implementation of precision farming practices results in higher reductions than in farm 1.

Table 4. GHG emissions.

\begin{tabular}{|c|c|c|c|c|}
\hline \multirow[b]{2}{*}{ REF } & \multicolumn{2}{|c|}{ Farm 1} & \multicolumn{2}{|c|}{ Farm 2} \\
\hline & $\begin{array}{c}\text { Methane } \\
\text { (g CH} 4 / k g \text { DOM) }\end{array}$ & $\begin{array}{c}\text { Nitrous Oxide } \\
\left(\mathrm{kg} \mathrm{N}-\mathrm{N}_{2} \mathrm{O} / \mathrm{kg} \mathrm{N}\right)\end{array}$ & $\begin{array}{c}\text { Methane } \\
\text { (g CH} 4 / k g \text { DOM) }\end{array}$ & $\begin{array}{c}\text { Nitrous Oxide } \\
\left(\mathrm{kg} \mathrm{N}-\mathrm{N}_{2} \mathrm{O} / \mathrm{kg} \mathrm{N}\right)\end{array}$ \\
\hline Baseline & 0.58 & 0.04 & 0.61 & 0.06 \\
\hline Scenario 1 & 0.51 & 0.19 & 0.55 & 0.028 \\
\hline Scenario 2 & 0.51 & 0.082 & 0.55 & 0.028 \\
\hline
\end{tabular}




\section{Discussion and Conclusions}

In this study, we attempted to analyze farmers' adoption decisions towards BioCircular farming practices in two characteristic cow dairy farms in Central Greece. Moreover, we tried to examine the impact of this adoption on the economic and environmental outcomes of the examined farming systems. In order to achieve this, a bio-economic model was developed and applied through different simulated scenarios.

Our findings, based on these simulated scenarios, highlighted different findings. In general, both farmers seemed motivated to adopt the innovative practices in both animal and crop production. This was the case mostly because the novel practices led to lower input costs and because of the presence of the premium in scenario 2 . Indeed, the expected Gross-Margins for both farms increased from 1 to $3 \%$ and from 10 to $17 \%$. Moreover, the adoption of the proposed practices led to significant decreases in GHG emissions. Similar findings are reported based on the use of bio-economic models in the study of Mosnier et al. [21]. In this study, four different bio-economic models were tested in order to examine farmers' adoption processes of innovative practices in terms of the economic profitability of the French dairy systems and the reduction in GHG emissions. According to their findings, the adoption of precision-agricultural findings by the French dairy farms may increase their profitability by $2 \%$ without harming their milk production, while a reduction in GHG emissions of up to $6 \%$ may be attainable.

Similarly, the study of Abas et al. [1] examined the economic and environmental potentials of the Greek dairy farms through the use of a Multinomial Logit Model. According to their findings, the great majority of the examined farms have the financial means to become economically and environmentally viable through the adoption of precision farming practices. However, there is an imminent need for policy support in order to promote and support this initiative.

Towards this direction, we showed that different policy measures may be efficiently targeted in order to motivate farmers to overcome their risk aversion. In fact, we showed that both premiums and penalties may mobilize farmers to adopt precision-agricultural practices in crop and animal production. However, the levels of these measures depend heavily on the labor availability of the production systems. In fact, the biggest barrier for the adoption of BioCircular practices is the increasing labor demands that the new practices need. Indeed, this finding is in accordance with an increasing body of literature that includes labor and labor reallocation as an important determinant in farmers' adoption processes $[14,22,23]$. Consequently, the levels of premiums or penalties should be higher in farm 1 than in farm 2, as the first one has lower labor availability.

Another important finding is that premiums are more effective than penalties in convincing farmers to adopt alternative practices, as they can ameliorate challenges to the economic and environmental performance of the examined farms. This is in accordance with many studies that support the superiority of incentives over penalties [24,25]. Nevertheless, it must be stated that the implementation of incentives, such as AESs or eco-schemes, entails an important social cost.

In this context, our simulations revealed that the proposed subsidies vary between $€ 29 /$ cow and $€ 242 /$ cow. These premiums are significantly lower than the existing ones coming from the first pillar of CAP [3]. This result permits us to state that effective targeting of environmental measures may contribute to both the effectiveness of the existing policy measures and to the reduction in related social costs. However, the above findings are subject to a number of simplifications. First of all, the capture of all GHG emissions is a rather difficult procedure, especially for animal production. Here, we attempted to estimate the methane emissions during the feeding process and during the stay of the animals within the buildings. However, as many factors may intervene in the emission of methane, more data need to be collected and added in our modeling process. Moreover, the emissions of nitrous oxide vary during the manure collection and treatment. These variations were not considered in our modeling attempt [20]. In addition, we did not include an indicator about carbon dioxide emissions for both crop and animal production due to a lack of data. Finally, 
there is no analysis regarding the effects of different feeds on animal milk production and on methane emissions [10]. Therefore, a significant amount of data is needed in order to reinforce the outcomes of our model and to strengthen our conclusions.

Author Contributions: Conceptualization, G.K. and L.S.K.; methodology, G.K.; software, G.K. and L.S.K.; validation, G.K., L.S.K. and C.K.; formal analysis, C.K.; investigation, G.K.; resources, A.C.T.; data curation, C.K.; writing-original draft preparation, G.K.; writing-review and editing, G.K., L.S.K. and A.C.T.; visualization, G.K.; supervision, D.B.; project administration, A.C.T. and D.B.; funding acquisition, A.C.T. and D.B. All authors have read and agreed to the published version of the manuscript.

Funding: This work was supported by the European Union and Greek national funds through the "Competitiveness, Entrepreneurship and Innovation" Operational Programme, under the call "RESEARCH-CREATE-INNOVATE" (project code: T1EDK-03987), as part of the "BioCircular: Bioproduction System for Circular Precision Farming" project.

Informed Consent Statement: Not applicable.

Data Availability Statement: Not applicable.

Conflicts of Interest: The authors declare no conflict of interest.

\section{References}

1. Abas, Z.; Ragkos, A.; Mitsopoulos, I.; Theodoridis, A. The Environmental Profile of Dairy Farms in Central Macedonia (Greece). Procedia Technol. 2013, 8, 378-386. [CrossRef]

2. Siafakas, S.; Tsiplakou, E.; Kotsarinis, M.; Tsiboukas, K.; Zervas, G. Identification of efficient dairy farms in Greece based on home grown feedstuffs, using the Data Envelopment Analysis method. Livest. Sci. 2019, 222, 14-20. [CrossRef]

3. Gourdouvelis, D.; Dotas, V.; Kaimakamis, I.; Zagorakis, K.; Yiakoulaki, M. Typology and structural characterisation of suckler cow farming system in Central Macedonia, Greece. Ital. J. Anim. Sci. 2019, 18, 1082-1092. [CrossRef]

4. Ragkos, A.; Theodoridis, A.; Fachouridis, A.; Batzios, C. Dairy Farmers' Strategies against the Crisis and the Economic Performance of Farms. Procedia Econ. Financ. 2015, 33, 518-527. [CrossRef]

5. $\quad$ Eggleston, H.S.; Miwa, K.; Srivastava, N.; Tanabe, K. IPCC 2006 IPCC Guidelines for National Greenhouse Inventories-A Primer; The National Greenhouse Gas Inventories Programme: Kanagawa, Japan, 2006.

6. Sintori, A.; Liontakis, A.; Tzouramani, I. Assessing the environmental efficiency of greek dairy sheep farms: GHG emissions and mitigation potential. Agriculture 2019, 9, 28. [CrossRef]

7. Pérez Domínguez, I.; Fellmann, T.; Weiss, F.; Witzke, H.-P.; Barreiro-Hurle, J.; Himics, M.; Jansson, T.; Salputra, G.; Leip, A. An Economic Assessment of GHG Mitigation Policy Options for EU Agriculture; European Union: Luxembourg, 2015; Volume EUR27973, ISBN 978-92-79-59362-8.

8. Tagarakis, A.C.; Dordas, C.; Lampridi, M.; Kateris, D.; Bochtis, D. A Smart Farming System for Circular Agriculture. Eng. Proc. 2021, 9, 10. [CrossRef]

9. Fischer, A.; Edouard, N.; Faverdin, P. Precision feed restriction improves feed and milk efficiencies and reduces methane emissions of less efficient lactating Holstein cows without impairing their performance. J. Dairy Sci. 2020, 103, 4408-4422. [CrossRef]

10. Ngwabie, N.M.; Jeppsson, K.H.; Gustafsson, G.; Nimmermark, S. Effects of animal activity and air temperature on methane and ammonia emissions from a naturally ventilated building for dairy cows. Atmos. Environ. 2011, 45, 6760-6768. [CrossRef]

11. Lien, G.; Hardaker, J.B. Whole-farm planning under uncertainty: Impacts of subsidy scheme and utility function on portfolio choice in Norwegian agriculture. Eur. Rev. Agric. Econ. 2001, 28, 17-37. [CrossRef]

12. Sunding, D.; Zilberman, D. The Agricultural Innovation Process. Handb. Agric. Econ. 2001, 1, $207-261$.

13. Mosnier, C.; Ridier, A.; Képhaliacos, C.; Carpy-Goulard, F. Economic and environmental impact of the CAP mid-term review on arable crop farming in South-western France. Ecol. Econ. 2009, 68, 1408-1416. [CrossRef]

14. Kleftodimos, G.; Gallai, N.; Rozakis, S.; Képhaliacos, C. A farm-level ecological-economic approach of the inclusion of pollination services in arable crop farms. Land Use Policy 2021, 107, 105462. [CrossRef]

15. Havlík, P.; Veysset, P.; Boisson, J.M.; Lherm, M.; Jacquet, F. Joint production under uncertainty and multifunctionality of agriculture: Policy considerations and applied analysis. Eur. Rev. Agric. Econ. 2005, 32, 489-515. [CrossRef]

16. Hardaker, J.B.; Lien, G. Rationalising Risk Assessment: Applications to Agricultural Business. Aust. Agribus. Rev. $2007,15,93$.

17. Norton, R.D.; Hazell, P.B. Mathematical Programming for Economic Analysis in Agriculture; Macmillan Publ. Co.: New York, NY, USA, 1986.

18. Anderson, J.R. Coping with Risk in Agriculture; CABI Publishing: Delemont, Switzerland, 2009; ISBN 9780851998312.

19. Henke, R.; Maria Pupo D'Andrea Benos, T. Implementation of the first pillar of the CAP 2014-2020 in the EU Member States. Eur. Union 2015, 135. [CrossRef]

20. Mosnier, C.; Duclos, A.; Agabriel, J.; Gac, A. Orfee: A bio-economic model to simulate integrated and intensive management of mixed crop-livestock farms and their greenhouse gas emissions. Agric. Syst. 2017, 157, 202-215. [CrossRef] 
21. Mosnier, C.; Britz, W.; Julliere, T.; De Cara, S.; Jayet, P.A.; Havlík, P.; Frank, S.; Mosnier, A. Greenhouse gas abatement strategies and costs in French dairy production. J. Clean. Prod. 2019, 236, 117589. [CrossRef]

22. Kleftodimos, G.; Gallai, N.K.C. Ecological-economic modeling of pollination complexity and pesticide use in agricultural crops _Enhanced Reader.pdf. J. Bioecon. 2021, 23, 297-323. [CrossRef]

23. Ridier, A.; Ben El Ghali, M.; Nguyen, G.; Kephaliacos, C. The Role of Risk Aversion and Labor Constraints in the Adoption of Low Input Practices Supported by the CAP Green Payments in Cash Crop Farms. Rev. D'etudes Agric. Environ. 2013, 94, 195-219. [CrossRef]

24. Colen, L.; Gomez y Paloma, S.; Latacz-Lohmann, U.; Lefebvre, M.; Préget, R.; Thoyer, S. Economic Experiments as a Tool for Agricultural Policy Evaluation: Insights from the European CAP. Can. J. Agric. Econ. 2016, 64, 667-694. [CrossRef]

25. Lefebvre, M.; Langrell, S.R.H.; Gomez-y-Paloma, S. Incentives and policies for integrated pest management in Europe: A review. Agron. Sustain. Dev. 2015, 35, 27-45. [CrossRef] 